\title{
Health state utility values (QALY weights) for Huntington's disease: an analysis of data from the European Huntington's Disease Network (EHDN)
}

\author{
Annie Hawton ${ }^{1}\left[\right.$. Colin Green ${ }^{1} \cdot$ Elizabeth Goodwin ${ }^{1} \cdot$ Timothy Harrower $^{2}$
}

Received: 27 August 2018 / Accepted: 31 July 2019 / Published online: 13 August 2019

(c) The Author(s) 2019

\begin{abstract}
Background Huntington's Disease (HD) is a hereditary neurodegenerative disorder which affects individuals' ability to walk, talk, think, and reason. Onset is usually in the forties, there are no therapies currently available that alter disease course, and life expectancy is 10-20 years from diagnosis. The gene causing HD is fully penetrant, with a 50\% probability of passing the disease to offspring. Although the impacts of HD are substantial, there has been little report of the quality of life of people with the condition in a manner that can be used in economic evaluations of treatments for HD. Health state utility values (HSUVs), used to calculate quality-adjusted life-years (QALYs), are the metric commonly used to inform such healthcare policy decision-making.

Objectives The aim was to report HSUVs for HD, with specific objectives to use European data to: (i) describe HSUVs by demographic and clinical characteristics; (ii) compare HSUVs of people with HD in the UK with population norms; (iii) identify the relative strength of demographic and clinical characteristics in predicting HSUVs.

Methods European Huntington's Disease Network REGISTRY study data were used for analysis. This is a multi-centre, multi-national, observational, longitudinal study, which collects six-monthly demographic, clinical, and patient-reported outcome measures, including the SF-36. SF-36 scores were converted to SF-6D HSUVs and described by demographic and clinical characteristics. HSUVs from people with HD in the UK were compared with population norms. Regression analysis was used to estimate the relative strength of age, gender, time since diagnosis, and disease severity (according to the Total Function Capacity (TFC) score, and the UHDRS's Motor score, Behavioural score, and Cognition score) in predicting HSUVs.

Results 11,328 questionnaires were completed by 5560 respondents with HD in 12 European countries. Women generally had lower HSUVs than men, and HSUVs were consistently lower than population norms for those with HD in the UK, and dropped with increasing disease severity. The regression model significantly accounted for the variance in SF-6D scores $(n=1939 ; F[7,1931]=120.05 ; p<0.001$; adjusted R-squared 0.3007), with TFC score, Behavioural score, and male gender significant predictors of SF-6D values $(p<0.001)$.

Conclusion To our knowledge, this is the first report of HSUVs for HD for countries other than the UK, and the first report of SF-6D HSUVs described for 12 European countries, according to demographic and clinical factors. Our analyses provide new insights into the relationships between HD disease characteristics and assessment of health-related quality of life in a form that can be used in policy-relevant economic evaluations.
\end{abstract}

Keywords Huntington's disease $\cdot$ Health state utility values $\cdot$ Quality-adjusted life-years $\cdot$ Cost-effectiveness analysis

Electronic supplementary material The online version of this article (https://doi.org/10.1007/s10198-019-01092-9) contains supplementary material, which is available to authorized users.

Annie Hawton

a.hawton@exeter.ac.uk

Extended author information available on the last page of the article 
JEL Classification I19

\section{Background}

Huntington's Disease (HD) is a hereditary neurodegenerative disorder which results in a number of motor, cognitive, and psychiatric symptoms. The condition is characterised by involuntary movements, known as chorea, and an impairment of voluntary movements. Learning and memory problems, depression, obsessive compulsive disorder, and psychosis are frequently reported, as are personality and behaviour changes including apathy, irritability, impulsivity, and obsessionality [1].

HD onset usually occurs when individuals are in their forties, there are no therapies currently available that alter the disease course, and people with HD tend to live only 10-20 years from diagnosis. The gene which causes HD is fully penetrant [2], and it has a devastating effect on an individual's ability to walk, think, talk and reason [1]. In addition, individuals with HD have a 50\% chance of passing the disease onto their children [3]. Diagnosis can have major implications which affect not only the person with $\mathrm{HD}$, but also the rest of the family who may also be at risk of developing the disease [4].

The disorder is relatively uncommon. For example, in 2012, a systematic review and meta-analysis estimated that there was an overall prevalence of adults with HD in Europe, North America, and Australia of 5.7 per 100,000 people [5]. Hence, despite its devastating impact on affected families, HD receives little attention at a national, or international, level. For example, the National Institute for Health and Care Excellence (NICE) [6], which provides guidelines for resource allocation regarding health and social care in the UK, makes no specific reference to the funding of treatments for people with HD.

The breadth of the personal, social, and economic impact of HD has, to date, been under-explored. Research by Busse et al. [7], utilising data from the European Huntington's Disease Network (EHDN), has been fundamental to starting to establish the health, social, and economic impacts of HD. This work has estimated the proportions of people with HD who use formal and informal care services, and has explored relationships between resource use, disease severity and functional ability. However, to date, no research is apparent which has reported the health-related quality of life (HRQoL) of people with HD in a manner that can be used in policy-relevant economic evaluations of treatments for the condition.

Health outcomes, in the context of health policy decisionmaking, are frequently considered in the form of qualityadjusted life-years (QALYs). QALYs combine quantity and quality of life in a single outcome measure, whereby length of life is adjusted by a weight representing the quality of life during that time. These quality weights, which are often referred to as health state utility values (HSUVs), can be estimated from preference-based measures [8]. Two of the most commonly used preference-based measures internationally are the EQ-5D [9] and the SF-6D [10].

We conducted a systematic review of HSUVs for HD. This identified just two relevant studies [11] [12]. Research by Hocaoglu et al. [11] focussed on exploring patient-proxy ratings of $\mathrm{HRQOL}$ at different stages of $\mathrm{HD}$ and investigated the factors which affect proxy ratings, whilst the study by Calvert et al. [12] considered the impact of rare long-term neurological conditions, including HD, on people's HRQoL. Both studies were conducted in the UK and included samples of 105 and 53 people with HD, respectively. The EQ-5D was used in both studies and no breakdown was provided by demographic or clinical characteristics or disease staging. As such, very little is documented about HSUVs of people with HD.

\section{Aims}

The aims of this research were:

- to describe HSUVs for HD by demographic and clinical characteristics, using data from a European longitudinal, observational study;

- to compare HSUVs of people in the UK with HD with population norms;

- to identify the relative strength of demographic and clinical characteristics in predicting HSUVs for HD.

\section{Methods}

\section{Participants}

Data from the European Huntington's Disease Network REGISTRY study [13] were used for analysis. This is a multi-centre, multi-national, observational, longitudinal study of people with HD across Europe. Participants complete a six-monthly battery of demographic, clinical, and patient-reported outcome measures, including gender, age, time since diagnosis, disease severity stage according to the Shoulson-Fahn Functional Capacity Rating Scale [14] and motor, cognitive, functional, and behavioural symptoms as rated by the United Huntington's Disease Rating Scale (UHDRS) [15], and the SF-36. Participants enrolled in the REGISTRY study provide informed, written consent for 
their anonymised data to be used for research purposes. All those who had provided initial data as of October 2014 were included in the following analyses.

\section{Measures}

\section{United Huntington's Disease Rating Scale (UHDRS) [15]}

The UHDRS was developed as a clinical rating scale to assess four domains relating to the clinical features of HD and the course of the disease: motor function, cognitive function, behavioural difficulties, and functional capacity. The measure has undergone extensive reliability and validity testing and has been used as a primary outcome measure in a number of controlled clinical trials. The domains are scored separately, as follows.

Total Functional Capacity (TFC) This rates a person's independence, using Likert scales, in terms of five domains (occupation, ability to manage finances, ability to perform domestic chores, ability to perform personal activities of daily living, and setting for level of care). The score is the sum of Likert responses (0-3, or 0-2) to five items. Scores range from 0 to 13 , with higher scores indicating higher functional capacity. A score of $13 / 13$ is possible on the TFC. This corresponds to functional independence of an individual who has been diagnosed with HD, but has no symptoms.

Behavioural score This is the sum of Likert responses (scored 0-4) which rate the frequency and the severity of 11 behavioural symptoms (e.g., sad/mood, low selfesteem/guilt, disruptive or aggressive behaviour, obsessions, hallucinations, and irritable behaviour). Scores can range from 0 to 88 , with higher scores indicative of increased problems.

Cognition score This is the sum of raw scores (number of correct responses) to five cognitive tests. These are a phonemic verbal fluency test (the Controlled Oral Word Association test [16], the Symbol Digit Modalities test [17], and three scores generated from the Stroop Color and Word tests [18]. Higher scores are indicative of better functioning.

Motor score This is the sum of Likert responses (scored 0-4) to 31 motor symptoms items, e.g., ocular pursuit, maximal chorea, gait, and tongue protrusion). Scores range from 0 to 124 , with higher scores indicating greater impairment.

\section{Shoulson-Fahn Functional Capacity Rating Scale [19]}

The TFC score can be used to categorise people into five disease stages defined by the Shoulson-Fahn Functional Capacity Rating Scale. Stage I (earliest stage) includes scores 11-13, Stage II scores 7-10, Stage III scores 3-6, Stage IV scores 1-2, and Stage V score 0 (most advanced stage). Individuals in Stage I may be pre-manifest, i.e., they may have been diagnosed with the condition via genetic testing, but have no clinical expression, Stage II can be characterised by issues with work and some impairment with usual activities, Stage III may include problems with activities of daily living and the requirement for some care support, Stage IV indicates the need for assistance with most activities of daily living and $24 \mathrm{~h}$ care may be appropriate, and Stage V is indicative of requiring support with all activities of daily living and progression to the terminal phase of the condition.

\section{Sf-36/Sf-6d [20]}

The SF-36 includes 36 self-report questions which assess functional health and well-being from the patient's perspective over the previous 4 weeks [20]. The measure is one of the most widely used tools worldwide for measuring patientreported outcomes. Participant responses to the SF-36 were converted to SF-6D values using the algorithm provided by Brazier et al. (2002). The SF-6D [10] is a preference-based measure of health, which provides health state utility values. Scores on the SF-6D can range from 0.3 to 1.0 , where 0.3 indicates the worst health state and 1.0 the best health state.

\section{Data analyses}

Mean (SD) SF-6D HSUVs were described by gender, age (under 35 years, 35-44 years, 45-54 years, 55-64 years, and 65 years and over), time since diagnosis (1-4 years, 5-9 years, 10 years or more), and disease stage according to the Shoulson-Fahn Functional Capacity Rating Scale (Stage I, Stage II, Stage III, and Stage IV/V). The values were described individually for the 12 European countries and across the countries as a whole. The SF-6D values from people with HD in the UK were compared with SF-6D norms for a representative sample of the UK population, reported by age [21].

A random-effects linear regression analysis was conducted to estimate the relative strength of age, gender, time since diagnosis, and disease severity (according to the Total Functional Capacity score, and the UHDRS's Motor score, Behavioural score, and Cognition score), in predicting SF-6D values when respondents first provided data to the REGISTRY study. Standardized beta coefficients were 
Table 1 SF-6D health state utility values by gender

\begin{tabular}{|c|c|c|c|c|c|c|}
\hline & Mean & Standard deviation & Min & Max & Observations & Individuals \\
\hline \multicolumn{7}{|c|}{ All countries } \\
\hline Female & 0.695054 & 0.144963 & 0.3 & 1 & 5774 & 2836 \\
\hline Male & 0.707324 & 0.140701 & 0.3 & 1 & 5153 & 2549 \\
\hline \multicolumn{7}{|l|}{ Austria } \\
\hline Female & 0.752955 & 0.137642 & 0.35 & 1 & 88 & 51 \\
\hline Male & 0.783546 & 0.136137 & 0.42 & 1 & 110 & 58 \\
\hline \multicolumn{7}{|l|}{ France } \\
\hline Female & 0.647912 & 0.135184 & 0.3 & 1 & 795 & 360 \\
\hline Male & 0.666512 & 0.138597 & 0.3 & 1 & 691 & 324 \\
\hline \multicolumn{7}{|l|}{ Germany } \\
\hline Female & 0.695595 & 0.149368 & 0.3 & 1 & 1135 & 571 \\
\hline Male & 0.701092 & 0.134925 & 0.32 & 1 & 1026 & 497 \\
\hline \multicolumn{7}{|l|}{ Italy } \\
\hline Female & 0.675282 & 0.129783 & 0.3 & 1 & 248 & 161 \\
\hline Male & 0.700493 & 0.12746 & 0.32 & 1 & 223 & 146 \\
\hline \multicolumn{7}{|c|}{ Netherlands } \\
\hline Female & 0.71235 & 0.141317 & 0.3 & 1 & 532 & 245 \\
\hline Male & 0.704964 & 0.125869 & 0.41 & 1 & 415 & 182 \\
\hline \multicolumn{7}{|l|}{ Norway } \\
\hline Female & 0.726213 & 0.141851 & 0.36 & 1 & 272 & 73 \\
\hline Male & 0.767959 & 0.139001 & 0.39 & 1 & 245 & 85 \\
\hline \multicolumn{7}{|l|}{ Poland } \\
\hline Female & 0.696908 & 0.133193 & 0.32 & 1 & 705 & 363 \\
\hline Male & 0.686235 & 0.134987 & 0.3 & 1 & 595 & 315 \\
\hline \multicolumn{7}{|l|}{ Portugal } \\
\hline Female & 0.689557 & 0.156728 & 0.34 & 1 & 384 & 136 \\
\hline Male & 0.708045 & 0.156622 & 0.3 & 1 & 266 & 108 \\
\hline \multicolumn{7}{|l|}{ Spain } \\
\hline Female & 0.708491 & 0.150103 & 0.3 & 1 & 636 & 375 \\
\hline Male & 0.722517 & 0.153181 & 0.32 & 1 & 588 & 337 \\
\hline \multicolumn{7}{|l|}{ Sweden } \\
\hline Female & 0.745081 & 0.164067 & 0.33 & 1 & 124 & 52 \\
\hline Male & 0.725755 & 0.144714 & 0.33 & 1 & 139 & 54 \\
\hline \multicolumn{7}{|c|}{ Switzerland } \\
\hline Female & 0.722208 & 0.13359 & 0.35 & 1 & 77 & 35 \\
\hline Male & 0.699677 & 0.12578 & 0.43 & 0.96 & 93 & 37 \\
\hline \multicolumn{7}{|l|}{ UK } \\
\hline Female & 0.698362 & 0.142428 & 0.3 & 1 & 769 & 405 \\
\hline Male & 0.726599 & 0.136859 & 0.3 & 1 & 741 & 390 \\
\hline
\end{tabular}

computed to directly compare the strength of prediction of each of the independent variables [beta coefficients are regression coefficients obtained by first standardising all variables to a mean of 0 and a standard deviation of 1]. A second regression analysis was conducted as above with the addition of country of residence as 12 binary independent variables, i.e., resident of country $X(0)$ or not resident of country $X(1)$.

Multi-collinearity was assessed by checking correlations between the independent variables, by use of the _rmdcoll in STATA, prior to inclusion in the regression analysis. The adequacy of the model fit was reviewed by examining a normality plot of residuals and a scatterplot of predicted values versus residual values. All analyses were conducted in Excel and STATA 12, and $p$ values of less than 0.05 were considered to be statistically significant. 
Table 2 SF-6D health state utility values by age group

\begin{tabular}{|c|c|c|c|c|c|c|}
\hline & Mean & Standard deviation & Min. & Max. & Observations & Individuals \\
\hline \multicolumn{7}{|l|}{ All countries } \\
\hline Under 35 years & 0.760387 & 0.139523 & 0.3 & 1 & 1811 & 1055 \\
\hline $35-44$ years & 0.717771 & 0.145022 & 0.3 & 1 & 2660 & 1451 \\
\hline $45-54$ years & 0.687817 & 0.138592 & 0.3 & 1 & 2822 & 1557 \\
\hline $55-64$ years & 0.674979 & 0.135299 & 0.3 & 1 & 2326 & 1211 \\
\hline 65 years and over & 0.658051 & 0.136079 & 0.3 & 1 & 1308 & 700 \\
\hline \multicolumn{7}{|l|}{ Austria } \\
\hline Under 35 years & 0.811 & 0.102387 & 0.64 & 1 & 20 & 13 \\
\hline $35-44$ years & 0.809275 & 0.156283 & 0.35 & 1 & 69 & 34 \\
\hline $45-54$ years & 0.736078 & 0.136427 & 0.42 & 1 & 51 & 36 \\
\hline $55-64$ years & 0.756061 & 0.102681 & 0.53 & 1 & 33 & 17 \\
\hline 65 years and over & 0.716 & 0.113284 & 0.51 & 0.93 & 25 & 16 \\
\hline \multicolumn{7}{|l|}{ France } \\
\hline Under 35 years & 0.730351 & 0.148846 & 0.36 & 1 & 171 & 86 \\
\hline $35-44$ years & 0.670348 & 0.13492 & 0.3 & 1 & 345 & 175 \\
\hline $45-54$ years & 0.641503 & 0.125873 & 0.3 & 1 & 386 & 205 \\
\hline $55-64$ years & 0.648115 & 0.133238 & 0.3 & 1 & 382 & 192 \\
\hline 65 years and over & 0.615297 & 0.132804 & 0.34 & 1 & 202 & 113 \\
\hline \multicolumn{7}{|l|}{ Germany } \\
\hline Under 35 years & 0.774379 & 0.131078 & 0.38 & 1 & 338 & 203 \\
\hline $35-44$ years & 0.721186 & 0.148078 & 0.33 & 1 & 531 & 294 \\
\hline $45-54$ years & 0.692475 & 0.135764 & 0.3 & 1 & 602 & 339 \\
\hline $55-64$ years & 0.659823 & 0.126737 & 0.3 & 1 & 451 & 239 \\
\hline 65 years and over & 0.626276 & 0.131203 & 0.32 & 1 & 239 & 112 \\
\hline \multicolumn{7}{|l|}{ Italy } \\
\hline Under 35 years & 0.695273 & 0.137354 & 0.38 & 1 & 55 & 46 \\
\hline $35-44$ years & 0.699573 & 0.131722 & 0.37 & 0.97 & 117 & 81 \\
\hline $45-54$ years & 0.669833 & 0.131667 & 0.32 & 1 & 120 & 84 \\
\hline $55-64$ years & 0.681226 & 0.110028 & 0.35 & 0.93 & 106 & 72 \\
\hline 65 years and over & 0.69863 & 0.139695 & 0.3 & 1 & 73 & 43 \\
\hline \multicolumn{7}{|l|}{ Netherlands } \\
\hline Under 35 years & 0.739927 & 0.127738 & 0.39 & 1 & 137 & 75 \\
\hline $35-44$ years & 0.731773 & 0.148347 & 0.41 & 1 & 203 & 104 \\
\hline $45-54$ years & 0.704164 & 0.126814 & 0.32 & 1 & 269 & 142 \\
\hline $55-64$ years & 0.700437 & 0.128704 & 0.41 & 1 & 229 & 108 \\
\hline 65 years and over & 0.658624 & 0.132249 & 0.3 & 0.97 & 109 & 59 \\
\hline \multicolumn{7}{|l|}{ Norway } \\
\hline Under 35 years & 0.766897 & 0.115017 & 0.55 & 1 & 58 & 26 \\
\hline $35-44$ years & 0.775417 & 0.142899 & 0.38 & 1 & 120 & 50 \\
\hline $45-54$ years & 0.731018 & 0.156396 & 0.36 & 1 & 167 & 59 \\
\hline 55-64 years & 0.724952 & 0.146842 & 0.39 & 1 & 103 & 43 \\
\hline 65 years and over & 0.744928 & 0.104031 & 0.51 & 1 & 69 & 23 \\
\hline \multicolumn{7}{|l|}{ Poland } \\
\hline Under 35 years & 0.740701 & 0.145356 & 0.3 & 1 & 385 & 217 \\
\hline $35-44$ years & 0.700069 & 0.128252 & 0.34 & 1 & 289 & 165 \\
\hline $45-54$ years & 0.66278 & 0.124237 & 0.32 & 0.96 & 259 & 147 \\
\hline $55-64$ years & 0.658906 & 0.120341 & 0.4 & 1 & 256 & 138 \\
\hline 65 years and over & 0.646847 & 0.102877 & 0.38 & 0.96 & 111 & 67 \\
\hline \multicolumn{7}{|l|}{ Portugal } \\
\hline Under 35 years & 0.789608 & 0.143568 & 0.42 & 1 & 153 & 59 \\
\hline $35-44$ years & 0.691326 & 0.153885 & 0.37 & 1 & 181 & 73 \\
\hline
\end{tabular}


Table 2 (continued)

\begin{tabular}{|c|c|c|c|c|c|c|}
\hline & Mean & Standard deviation & Min. & Max. & Observations & Individuals \\
\hline $45-54$ years & 0.662026 & 0.147543 & 0.36 & 1 & 153 & 69 \\
\hline 55-64 years & 0.645833 & 0.133548 & 0.34 & 1 & 96 & 48 \\
\hline 65 years and over & 0.655224 & 0.160022 & 0.3 & 0.96 & 67 & 32 \\
\hline \multicolumn{7}{|l|}{ Spain } \\
\hline Under 35 years & 0.794508 & 0.130217 & 0.33 & 1 & 244 & 177 \\
\hline $35-44$ years & 0.746099 & 0.144008 & 0.3 & 1 & 323 & 208 \\
\hline $45-54$ years & 0.687599 & 0.1457 & 0.34 & 1 & 279 & 180 \\
\hline $55-64$ years & 0.667126 & 0.153473 & 0.3 & 1 & 247 & 129 \\
\hline 65 years and over & 0.640992 & 0.132989 & 0.38 & 1 & 131 & 86 \\
\hline \multicolumn{7}{|l|}{ Sweden } \\
\hline Under 35 years & 0.763571 & 0.142834 & 0.34 & 0.89 & 28 & 16 \\
\hline $35-44$ years & 0.762245 & 0.134788 & 0.54 & 1 & 49 & 22 \\
\hline $45-54$ years & 0.743253 & 0.154723 & 0.33 & 1 & 83 & 35 \\
\hline $55-64$ years & 0.719385 & 0.17946 & 0.33 & 1 & 65 & 27 \\
\hline 65 years and over & 0.686579 & 0.128237 & 0.43 & 1 & 38 & 20 \\
\hline \multicolumn{7}{|l|}{ Switzerland } \\
\hline Under 35 years & 0.785517 & 0.119779 & 0.54 & 1 & 29 & 14 \\
\hline $35-44$ years & 0.691852 & 0.142452 & 0.45 & 0.93 & 27 & 17 \\
\hline $45-54$ years & 0.673778 & 0.116097 & 0.43 & 0.92 & 45 & 25 \\
\hline $55-64$ years & 0.681225 & 0.117874 & 0.35 & 0.93 & 49 & 19 \\
\hline 65 years and over & 0.776 & 0.122018 & 0.54 & 0.93 & 20 & 8 \\
\hline \multicolumn{7}{|l|}{ UK } \\
\hline Under 35 years & 0.756667 & 0.146746 & 0.3 & 1 & 183 & 114 \\
\hline $35-44$ years & 0.714822 & 0.140459 & 0.35 & 1 & 394 & 219 \\
\hline $45-54$ years & 0.712357 & 0.138297 & 0.32 & 1 & 403 & 231 \\
\hline $55-64$ years & 0.702671 & 0.134274 & 0.3 & 1 & 307 & 177 \\
\hline 65 years and over & 0.684036 & 0.13906 & 0.3 & 1 & 223 & 120 \\
\hline
\end{tabular}

\section{Results}

\section{Demographic and clinical characteristics}

11,328 questionnaires were available from 5560 respondents with HD. Data were provided from more than 12 European countries, including 1510 responses from the UK. The mean (SD) age of respondents was 48.6 (13.3) years and 53\% of the sample were female. The mean (SD) time since diagnosis was 4.5 (3.8) years.

Forty-six percent of the respondents were categorised as Stage I in terms of disease progression, 26\% Stage II, $21 \%$ Stage III, and 7\% Stage IV/V. The mean (SD) Total Functional Capacity (TFC) score was 9.04 (3.82), the mean (SD) Behavioural score 12.76 (11.78), the mean (SD) Cognition score 187.49 (85.69), and mean (SD) motor score 29.06 (23.33).

\section{SF-6D health state utility values according to demographic and clinical characteristics}

Ten thousand nine hundred and twenty-seven unique SF-6D scores were available from respondents from all the countries that the REGISTRY includes, with 10,897 SF-6D HSUVs specific to 12 countries. Unadjusted HSUVs are described below and presented in Tables 1, 2, 3, and 4, Figs. 1 and 2.

\section{Gender}

HSUVs are presented in Table 1 by gender for the countries as a whole and for each of the 12 countries separately. The general pattern was for women to have lower SF-6D values than men.

\section{Age}

Table 2 and Fig. 1 present SF-6D values by age group. The data show a decline in values with age. The comparison of 
Table 3 SF-6D health state utility values by time since diagnosis

\begin{tabular}{|c|c|c|c|c|c|c|}
\hline & Mean & Standard deviation & Min. & Max. & Observations & Individuals \\
\hline \multicolumn{7}{|l|}{ All countries } \\
\hline Under 1 year & 0.690792 & 0.14013 & 0.32 & 1 & 1401 & 1323 \\
\hline $1-4$ years & 0.683108 & 0.13482 & 0.3 & 1 & 3758 & 2255 \\
\hline $5-9$ years & 0.659088 & 0.13342 & 0.3 & 1 & 2346 & 1388 \\
\hline 10 years or more & 0.639765 & 0.12777 & 0.3 & 1 & 767 & 449 \\
\hline \multicolumn{7}{|l|}{ Austria } \\
\hline Under 1 year & 0.744286 & 0.14587 & 0.35 & 1 & 28 & 28 \\
\hline $1-4$ years & 0.786868 & 0.12872 & 0.4 & 1 & 83 & 51 \\
\hline $5-9$ years & 0.746444 & 0.12619 & 0.49 & 1 & 45 & 30 \\
\hline 10 years or more & 0.653636 & 0.11281 & 0.49 & 0.8 & 11 & 10 \\
\hline \multicolumn{7}{|l|}{ France } \\
\hline Under 1 year & 0.665258 & 0.12956 & 0.36 & 1 & 194 & 184 \\
\hline $1-4$ years & 0.652803 & 0.12739 & 0.3 & 1 & 610 & 355 \\
\hline 5-9 years & 0.622319 & 0.13019 & 0.3 & 1 & 401 & 233 \\
\hline 10 years or more & 0.571809 & 0.09988 & 0.3 & 0.85 & 94 & 55 \\
\hline \multicolumn{7}{|l|}{ Germany } \\
\hline Under 1 year & 0.684045 & 0.14096 & 0.32 & 1 & 267 & 255 \\
\hline $1-4$ years & 0.676967 & 0.12866 & 0.32 & 1 & 755 & 464 \\
\hline $5-9$ years & 0.659446 & 0.13117 & 0.3 & 1 & 469 & 297 \\
\hline 10 years or more & 0.649392 & 0.14043 & 0.3 & 1 & 181 & 108 \\
\hline \multicolumn{7}{|l|}{ Italy } \\
\hline Under 1 year & 0.683171 & 0.12795 & 0.37 & 1 & 82 & 78 \\
\hline $1-4$ years & 0.696809 & 0.12584 & 0.32 & 1 & 188 & 134 \\
\hline 5-9 years & 0.652072 & 0.12413 & 0.35 & 0.97 & 111 & 78 \\
\hline 10 years or more & 0.647407 & 0.15934 & 0.3 & 1 & 27 & 18 \\
\hline \multicolumn{7}{|l|}{ Netherlands } \\
\hline Under 1 year & 0.701318 & 0.13212 & 0.32 & 1 & 129 & 120 \\
\hline $1-4$ years & 0.691862 & 0.12623 & 0.3 & 1 & 333 & 197 \\
\hline $5-9$ years & 0.667908 & 0.11375 & 0.36 & 1 & 196 & 111 \\
\hline 10 years or more & 0.65 & 0.10821 & 0.41 & 1 & 60 & 36 \\
\hline \multicolumn{7}{|l|}{ Norway } \\
\hline Under 1 year & 0.731404 & 0.14487 & 0.41 & 1 & 57 & 53 \\
\hline $1-4$ years & 0.740581 & 0.13607 & 0.38 & 1 & 172 & 79 \\
\hline 5-9 years & 0.712447 & 0.14251 & 0.38 & 1 & 94 & 40 \\
\hline 10 years or more & 0.701892 & 0.10173 & 0.56 & 1 & 37 & 13 \\
\hline \multicolumn{7}{|l|}{ Poland } \\
\hline Under 1 year & 0.68426 & 0.126 & 0.38 & 1 & 277 & 263 \\
\hline $1-4$ years & 0.664209 & 0.12526 & 0.32 & 1 & 449 & 267 \\
\hline 5-9 years & 0.649503 & 0.11622 & 0.38 & 0.97 & 201 & 113 \\
\hline 10 years or more & 0.624286 & 0.09676 & 0.4 & 0.93 & 49 & 28 \\
\hline \multicolumn{7}{|l|}{ Portugal } \\
\hline Under 1 year & 0.660678 & 0.1595 & 0.36 & 1 & 59 & 53 \\
\hline $1-4$ years & 0.670094 & 0.15398 & 0.3 & 1 & 213 & 114 \\
\hline 5-9 years & 0.631615 & 0.14723 & 0.34 & 1 & 130 & 70 \\
\hline 10 years or more & 0.618438 & 0.13716 & 0.36 & 1 & 32 & 16 \\
\hline \multicolumn{7}{|l|}{ Spain } \\
\hline Under 1 year & 0.691752 & 0.15795 & 0.33 & 1 & 137 & 130 \\
\hline $1-4$ years & 0.683433 & 0.14167 & 0.38 & 1 & 300 & 210 \\
\hline 5-9 years & 0.657255 & 0.13866 & 0.3 & 1 & 255 & 147 \\
\hline 10 years or more & 0.608317 & 0.12365 & 0.32 & 0.89 & 101 & 61 \\
\hline
\end{tabular}


Table 3 (continued)

\begin{tabular}{llllllc}
\hline & Mean & Standard deviation & Min. & Max. & Observations & Individuals \\
\hline Sweden & & & & & & \\
Under 1 year & 0.690556 & 0.14293 & 0.46 & 0.93 & 18 & 17 \\
1-4 years & 0.733111 & 0.16335 & 0.34 & 1 & 90 & 48 \\
5-9 years & 0.707778 & 0.16237 & 0.33 & 1 & 81 & 39 \\
10 years or more & 0.695833 & 0.18923 & 0.33 & 1 & 12 & 7 \\
Switzerland & & & & & & 10 \\
Under 1 year & 0.764 & 0.11673 & 0.58 & 0.89 & 10 & 27 \\
1-4 years & 0.698269 & 0.1462 & 0.35 & 0.96 & 52 & 23 \\
5-9 years & 0.676216 & 0.10782 & 0.45 & 0.85 & 37 & 9 \\
10 years or more & 0.650526 & 0.1025 & 0.48 & 0.92 & 19 & 132 \\
UK & & & & & & 305 \\
Under 1 year & 0.725315 & 0.15276 & 0.36 & 1 & 143 & 205 \\
1-4 years & 0.692854 & 0.13305 & 0.35 & 1 & 508 & 88 \\
5-9 years & 0.677901 & 0.13128 & 0.3 & 1 & 324 & 144 \\
10 years or more & 0.675278 & 0.12062 & 0.32 & 0.92 & & \\
\hline
\end{tabular}

SF-6D values by age for people with HD in the UK with values from a representative sample of the UK general population shows SF-6D values of people with HD to be consistently lower than those without the condition in all age groups.

\section{Time since diagnosis}

Table 3 shows a negligible drop in values, as time since diagnosis increases.

\section{Disease stage}

Table 4 and Fig. 2 indicate that SF-6D values decrease as HD progresses, with the most substantial drop between Stage I and Stage II, both for all the countries combined and the UK separately.

\section{Strength of demographic and clinical characteristics in predicting HSUVs}

Checks for multi-collinearity indicated that it was appropriate to include all independent variables in the regression model, and examination of normality plots of the regression residuals and scatterplots of predicted SF-6D and residual values also indicated the appropriateness of this analysis (Appendices 1 and 2).

Table 5 presents the results of the regression analysis. The model significantly accounted for the variance in SF-6D scores $(n=1939 ; F[7,1931]=120.05 ; p<0.001$; adjusted R-squared 0.3007). TFC score, Behavioural score, and male gender were significant predictors of SF-6D values (all at $p<0.001$ ). The regression results for these variables indicated the following:

(i) The coefficient estimated for the TFC variable was 0.009 , indicating that an one point change in the TFC score (range 0-13) corresponded to a 0.009 change in SF-6D score. For example, a decline in independence for a person with HD from a position of functional independence with a TFC score of 13 (Stage I on the TFC scale) to a state of total dependence with a TFC score of 0 (Stage V on the TFC scale) has, on average, a corresponding decrease of 0.119 in their HSUV (i.e., a change of 13 points on the TFC scale equates to a decrease of 0.119 on the SF-6D $[13 * 0.0091764])$.

(ii) The coefficient for Behavioural score was 0.005, indicating that an increase in behavioural difficulties by one point corresponds to a drop in SF-6D score of 0.005 . This equates, for example, to an average drop in SF-6D value of 0.416 from having no behavioural difficulties (score of 0 ) to having the maximum score on the Behavioural scale (score of 88) [88*-0.0047258]. Given that a minimally important difference of 0.041 on the SF-6D has been reported [22], these drops in SF-6D scores in line with increased behavioural difficulties appear to have distinct clinical relevance.

(iii) On average, men have SF-6D values 0.019 points higher than women.

The beta weights for the independent variables (given in Table 5) show the relative strength of each of these as predictors of SF-6D values. By far, the strongest predictor was the frequency and severity of behaviour problems 
Table 4 SF-6D health state utility values by disease stage

\begin{tabular}{|c|c|c|c|c|c|c|}
\hline & Mean & Standard deviation & Min & $\operatorname{Max}$ & Observations & Individuals \\
\hline \multicolumn{7}{|l|}{ All countries } \\
\hline Stage I & 0.766802 & 0.131412 & 0.3 & 1 & 4991 & 2869 \\
\hline Stage II & 0.674682 & 0.128271 & 0.3 & 1 & 2753 & 1755 \\
\hline Stage III & 0.632616 & 0.120776 & 0.3 & 1 & 2282 & 1500 \\
\hline Stage IV or V & 0.574574 & 0.117588 & 0.3 & 1 & 774 & 571 \\
\hline \multicolumn{7}{|l|}{ Austria } \\
\hline Stage I & 0.84662 & 0.106234 & 0.57 & 1 & 71 & 43 \\
\hline Stage II & 0.794889 & 0.116163 & 0.52 & 1 & 45 & 32 \\
\hline Stage III & 0.683878 & 0.124697 & 0.35 & 0.96 & 49 & 35 \\
\hline Stage IV or V & 0.676957 & 0.137459 & 0.42 & 1 & 23 & 17 \\
\hline \multicolumn{7}{|l|}{ France } \\
\hline Stage I & 0.727054 & 0.12818 & 0.41 & 1 & 577 & 305 \\
\hline Stage II & 0.647201 & 0.123765 & 0.36 & 1 & 393 & 246 \\
\hline Stage III & 0.59593 & 0.113446 & 0.3 & 1 & 398 & 264 \\
\hline Stage IV or V & 0.544159 & 0.113143 & 0.3 & 1 & 113 & 93 \\
\hline \multicolumn{7}{|l|}{ Germany } \\
\hline Stage I & 0.762888 & 0.132533 & 0.38 & 1 & 987 & 588 \\
\hline Stage II & 0.683287 & 0.126591 & 0.3 & 1 & 505 & 328 \\
\hline Stage III & 0.625195 & 0.115707 & 0.32 & 0.96 & 435 & 290 \\
\hline Stage IV or V & 0.556803 & 0.109825 & 0.3 & 0.95 & 147 & 116 \\
\hline \multicolumn{7}{|l|}{ Italy } \\
\hline Stage I & 0.73257 & 0.119209 & 0.49 & 1 & 214 & 158 \\
\hline Stage II & 0.684516 & 0.123902 & 0.33 & 1 & 124 & 93 \\
\hline Stage III & 0.629579 & 0.108911 & 0.32 & 0.97 & 95 & 79 \\
\hline Stage IV or V & 0.582162 & 0.134001 & 0.3 & 0.85 & 37 & 32 \\
\hline \multicolumn{7}{|l|}{ Netherlands } \\
\hline Stage I & 0.772891 & 0.130058 & 0.44 & 1 & 422 & 231 \\
\hline Stage II & 0.674352 & 0.107185 & 0.36 & 1 & 239 & 152 \\
\hline Stage III & 0.656305 & 0.124521 & 0.3 & 1 & 203 & 128 \\
\hline Stage IV or V & 0.606986 & 0.10237 & 0.36 & 0.96 & 73 & 49 \\
\hline \multicolumn{7}{|l|}{ Norway } \\
\hline Stage I & 0.788699 & 0.135195 & 0.38 & 1 & 269 & 99 \\
\hline Stage II & 0.716343 & 0.141254 & 0.36 & 1 & 134 & 66 \\
\hline Stage III & 0.695222 & 0.1221 & 0.38 & 0.96 & 90 & 43 \\
\hline Stage IV or V & 0.626522 & 0.117922 & 0.39 & 0.88 & 23 & 17 \\
\hline \multicolumn{7}{|l|}{ Poland } \\
\hline Stage I & 0.758336 & 0.127962 & 0.4 & 1 & 607 & 367 \\
\hline Stage II & 0.651849 & 0.113278 & 0.39 & 0.97 & 357 & 231 \\
\hline Stage III & 0.625165 & 0.102667 & 0.3 & 0.96 & 273 & 171 \\
\hline Stage IV or V & 0.56459 & 0.090306 & 0.38 & 0.76 & 61 & 40 \\
\hline \multicolumn{7}{|l|}{ Portugal } \\
\hline Stage I & 0.754729 & 0.139255 & 0.36 & 1 & 387 & 153 \\
\hline Stage II & 0.637239 & 0.136918 & 0.38 & 1 & 134 & 78 \\
\hline Stage III & 0.588081 & 0.131201 & 0.3 & 1 & 99 & 61 \\
\hline Stage IV or V & 0.48579 & 0.123257 & 0.34 & 0.8 & 19 & 15 \\
\hline \multicolumn{7}{|l|}{ Spain } \\
\hline Stage I & 0.786346 & 0.133099 & 0.3 & 1 & 665 & 442 \\
\hline Stage II & 0.658841 & 0.126674 & 0.33 & 1 & 207 & 150 \\
\hline Stage III & 0.640556 & 0.119292 & 0.3 & 0.97 & 198 & 139 \\
\hline Stage IV or V & 0.565308 & 0.117455 & 0.32 & 0.96 & 130 & 77 \\
\hline
\end{tabular}


Table 4 (continued)

\begin{tabular}{lllllll}
\hline & Mean & Standard deviation & Min & Max & Observations & Individuals \\
\hline Sweden & & & & & & \\
Stage I & 0.788807 & 0.124229 & 0.51 & 1 & 109 & 56 \\
Stage II & 0.730538 & 0.156486 & 0.43 & 1 & 93 & 40 \\
Stage III & 0.667805 & 0.163623 & 0.33 & 1 & 41 & 30 \\
Stage IV or V & 0.586875 & 0.128152 & 0.33 & 0.77 & 16 & 10 \\
Switzerland & & & & & & 43 \\
Stage I & 0.777024 & 0.11373 & 0.45 & 1 & 84 & 21 \\
Stage II & 0.661667 & 0.107504 & 0.43 & 0.85 & 36 & 21 \\
Stage III & 0.648438 & 0.118624 & 0.35 & 0.96 & 32 & 15 \\
Stage IV or V & 0.601765 & 0.089109 & 0.45 & 0.76 & 17 & 332 \\
UK & & & & & & 296 \\
Stage I & 0.789353 & 0.123431 & 0.39 & 1 & 541 & 222 \\
Stage II & 0.689479 & 0.130967 & 0.35 & 1 & 461 & 81 \\
Stage III & 0.655718 & 0.121061 & 0.3 & 1 & 348 & 105 \\
Stage IV or V & 0.603048 & 0.120736 & 0.3 & 0.96 & & \\
\hline
\end{tabular}

\section{1 \\ Mean \\ SF-6D \\ 0.9}

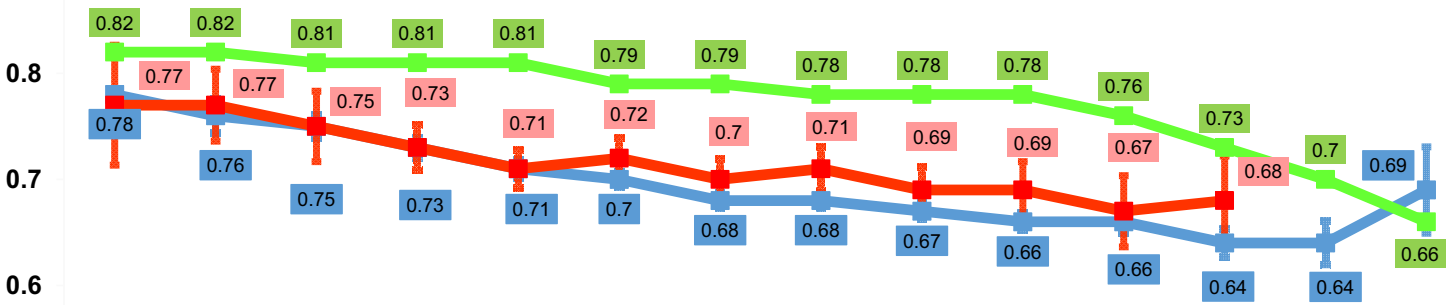

0.5

0.4

0.3

$\begin{array}{cccccccccccccc}20 \text { to } & 25 \text { to } & 30 \text { to } & 35 \text { to } & 40 \text { to } & 45 \text { to } & 50 \text { to } & 55 \text { to } & 60 \text { to } & 65 \text { to } & 70 \text { to } & 75 \text { to } & 80 \text { to } & 85+ \\ 24 & 29 & 34 & 39 & 44 & 49 & 54 & 59 & 64 & 69 & 74 & 79 & 84 & \text { Age (years) }\end{array}$

Fig. 1 Mean SF-6D health state utility values by age group

(Behavioural score, $\beta=-0.405$ ), followed by the degree of functional independence (TFC score, $\beta=0.233$ ). The next strongest predictor of higher HSUVs was male gen$\operatorname{der}(\beta=0.069)$, with the other predictors having relatively negligible effects. The results of the regression analysis including country of residence are shown in Appendix 3.

\section{Discussion}

To our knowledge, this is the first report of HSUVs for HD for countries other than the UK, and the first report of SF-6D values described individually for 12 European countries, broken down by demographic and clinical factors.

Our descriptive analysis indicated that women with HD generally had lower SF-6D HSUVs than men, and this finding held when gender was included in a regression analysis 
1

0.9

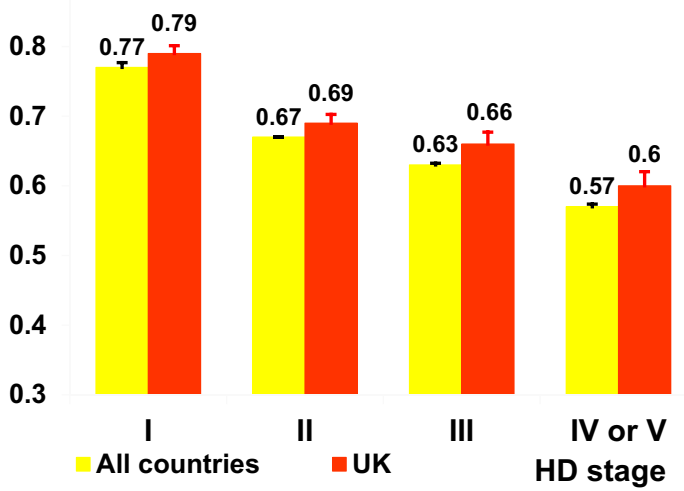

Fig. 2 Mean SF-6D health state utility values by disease stage

which controlled for other demographic and clinical variables. Although the descriptive data indicated a decline in HSUVs by age group, age was not statistically significantly associated with SF-6D values when other characteristics were controlled for. HSUVs declined by disease stage, with the most substantial drop between Stages I and II. This may be indicative of the fact that some individuals are diagnosed in the pre-manifest stage because of family history of the condition and early predictive testing, and experience no symptoms in Stage I [14]. This may also explain why there was not a statistically significant relationship between HSUVs and time since diagnosis, as some individuals may be diagnosed with HD and live for decades without any clinical expression, whilst others may only be diagnosed at the point of experiencing significant symptomatology.

The regression analysis indicated a significant association between HSUVs and behavioural symptoms, e.g., sadness/low mood, low self-esteem/guilt, disruptive or aggressive behaviour, obsessions, hallucinations, and irritable behaviour. This relationship was more substantial than the relationship between disease severity (as assessed by functional independence) and HSUVs, suggestive of the key role that such behavioural symptoms may play in HRQoL. Our analyses indicate the importance of these behavioural symptoms in the context of much less significant relationships between cognitive symptoms and HSUVs and motor symptoms and HSUVs, and reflect that although the clinical diagnosis of HD is based on the presence of the movement disorder, behavioural changes appear to be the most debilitating aspect of the condition [14]. People with HD are eight times more likely to commit suicide than other members of the general population [23], with HD fracturing lives of entire families: economically, socially, and emotionally. The impacts of HD appear far-reaching with a reported increased prevalence of criminal behaviour in males who carry the gene, and the suggestion that this criminal behaviour is probably linked to the personality changes exhibited as a result of the condition, or related to the depressive reactions to the illness coupled with secondary alcohol misuse [24].

The size and coverage of the European Huntington's Disease Network REGISTRY study data set has been a major asset for this research. It has enabled us to analyse HSUVs by key demographic variables and clinical factors pertinent to the condition across 12 European countries. Clearly, our results are constrained by the particular measures used in the REGISTRY study. The finding that behavioural symptoms were so strongly related to HSUVs, and cognitive and motor symptoms were not, may be indicative of the instruments used to assess these areas of functioning. However, each of these measures forms part of the United Huntington's Disease Rating Scale (UHDRS) [15], the main internationally recognised tool for assessing the symptoms of HD.

The ongoing, longitudinal data collection of the REGISTRY study provides a unique opportunity for future research

Table 5 Results of random-effects GLS regression to explore relationships between demographic and clinical variables and SF-6D health state utility values

\begin{tabular}{lrllrrr}
\hline SF-6D value & Coefficient & Standard error & $p>z$ & \multicolumn{2}{l}{$\begin{array}{l}\text { Lower confidence } \\
\text { interval }\end{array}$} & $\begin{array}{l}\text { Upper confidence } \\
\text { interval }\end{array}$ \\
\hline TFC score & 0.0091764 & 0.0011486 & 0.0000000 & 0.0069239 & 0.0114290 & 0.2328026 \\
Behavioural score & -0.0047258 & 0.0002288 & 0.0000000 & -0.0051744 & -0.0042771 & -0.4053759 \\
Cognition score & 0.0000891 & 0.0000596 & 0.1350000 & -0.0000278 & 0.0002060 & 0.0430957 \\
MOT score & -0.0002756 & 0.0002094 & 0.1880000 & -0.0006862 & 0.0001350 & -0.0384748 \\
Male gender & 0.0188754 & 0.0052631 & 0.0000000 & 0.0085535 & 0.0291973 & 0.0686814 \\
Age & -0.0002946 & 0.0002174 & 0.1760000 & -0.0007210 & 0.0001318 & -0.0270106 \\
Years since diagnosis & 0.0014575 & 0.0008332 & 0.0800000 & -0.0001766 & 0.0030917 & 0.0375215 \\
Constant & 0.6527599 & 0.0233794 & 0.0000000 & 0.6069084 & 0.6986114 & \\
\hline
\end{tabular}

$n=1939 ; F[7,1931]=120.05 ; p<0.001 ;$ Adjusted R-squared 0.3007

${ }^{a}$ Beta coefficients were obtained by standardising all variables to a mean of 0 and a standard deviation of 1 , and then including them in the regression analysis 
to consider the responsiveness of the SF-6D for people with HD over time, and in relation to treatments that are currently in development. Further research may also usefully explore the comparative responsiveness of the SF-6D and the EQ-5D to health-related changes in the lives of people with HD. The EQ-5D is the most common internationally used preferencebased measure for estimating QALYs, and is recommended for use by the UK's National Institute of Health and Care Excellence in health and social care policy decision-making [25]. It would be of value to determine whether changes in the HRQoL of people with HD are more/less likely to be detected by each of these economic evaluation measures, particularly given that the SF-6D provides higher HSUVs than the EQ-5D because the values are estimated using the standard gamble technique and respondents tend to be risk averse. This is evidenced here as our study found females with HD resident in the UK to have a mean (SD) SF-6D score of $0.698(0.142)$, whilst males had a mean (SD) score of 0.727 (0.137). In comparison, the two previous studies that included HSUVs of people with HD, both conducted in the UK, reported EQ-5D scores of a mean (standard deviation) of $0.56(0.35)$ [range -0.33 to 1] [11] and a mean ( $95 \%$ confidence interval) of $0.30(0.19,0.41)$ [12]. Thus, the SF-6D may demonstrate lower health gains relative to estimates based on the EQ-5D. The development of the international Enroll-HD platform [26] may provide additional opportunities to address some of these issues.

In conclusion, this research has provided new empirical data on the health state utility values associated with Huntington's disease, in a format that can inform the costeffectiveness analyses of treatments for people with HD. The provision of this information, based on assessments across a number of European countries, can aid health policy decision makers, clinicians, and people with HD.

Acknowledgements We would like to thank the EHDN REGISTRY Study Group investigators for collecting the data and all participating REGISTRY patients for their time and effort. The investigators of the EHDN are listed in full at: http://www.ehdn.org/.

Open Access This article is distributed under the terms of the Creative Commons Attribution 4.0 International License (http://creativeco mmons.org/licenses/by/4.0/), which permits unrestricted use, distribution, and reproduction in any medium, provided you give appropriate credit to the original author(s) and the source, provide a link to the Creative Commons license, and indicate if changes were made.

\section{References}

1. Walker, F.: Huntington's Disease. Lancet 369(1), 218-228 (2007)

2. Evans, S., Douglas, I., Rawlins, M.: Prevalence of adult Huntington's disease in the UK based on diagnoses recorded in general practice. J. Neurol. Neurosurg. Psychiatry 84(1), 1156-1160 (2013)
3. Chisholm, L., Flavin, K., Paulsen, J., Ready, R.: Psychological well-being in persons affected by Huntington's disease: a comparison of at risk, prodromal and symptomatic. J. Health Psychol. 18(2), 408-418 (2013)

4. Williams, J., Skirton, H., Barnette, J., Pulsen, J.: Family carer personal concerns in Huntington's disease. J. Adv. Nurs. 68(1), 137-146 (2012)

5. Pringsheim, T., Wiltshire, K., Day, L., Dykeman, J., Steeves, T., Jette, N.: The incidence and prevalence of Huntington's Disease: a systematic review and meta-analysis. Mov. Disord. 27(9), 10831091 (2012)

6. National Institute for Health and Care Excellence. http://guidance. nice.org.uk/ (2018). Accessed 27 Aug 2018

7. Busse M, AL-Madfa H, Kenke J, Landwehrmeyer G, Bentivoglia A. Utilisation of healthcare and associated services in Huntington's disease: a data mining study. PLOS Currents: Huntington Disease. 2010;1:1-15

8. Brazier, J., Ratcliffe, J., Salomon, J., Tsuchiya, A.: Measuring and valuing health benefits for economic evaluation. Oxford University Press, Oxford (2007)

9. Dolan, P.: Modeling valuations for EuroQol health states. Med. Care 35(11), 1095-1108 (1997)

10. Brazier, J., Roberts, J., Deverill, M.: The estimation of a preference-based single index measure for health from the SF-36. J. Health Econ. 21, 271-292 (2002)

11. Hocaoglu, M., Gaffan, E., Ho, A.: Health-related quality of life in Huntington's disease patients: a comparison of proxy assessment and patient self-rating using the disease-specific Huntington's disease health-related quality of life questionnaire (HDQoL). J. Neurol. 259(9), 1793-1800 (2012)

12. Calvert, M., Pall, H., Hoppitt, T., Eaton, B., Savill, E., Sackley, C.: Health-related quality of life and supportive care in patients with rare long-term neurological conditions. Qual. Life Res. 22(6), 1231-1238 (2013)

13. Orth, M., Handley, O., Schwenke, C., Dunnett, S., Craufurd, D., Ho, A., et al.: Observing Huntington's Disease: the European Huntington's Disease Network's REGISTRY. PLOS Curr. Huntingt. Dis. (2010). https://doi.org/10.1371/currents.rrn184. (Edition 1)

14. Nance, M., Paulsen, J., Rosenblatt, A., Wheelock, V.: A Physician's guide to the management of Huntington's Disease, 3rd edn. Huntington's Disease Society of America, New York (2011)

15. Huntington Study Group (Kieburtz K primary author): The Unified Huntington's Disease rating scale: reliability and consistency. Mov. Dis. 11, 136-142 (1996)

16. Benton, A., Hamsher, K., Varney, N., Spreen, O.: Contributions to neuropsychological assessment: a clinical manual. Oxford University Press, New York (1983)

17. Smith, A.: Symbol digit modalities test: manual. Western Psychological Corporation, Los Angeles (2002)

18. Stroop, J.: Studies of interference in serial verbal reactions. J. Exp. Psychol. 18(6), 643 (1935)

19. Shoulson, I., Kurlan, R., Rubin, A., et al.: Assessment of functional capacity in neurodegenerative movement disorders: Huntington's disease as a prototype. In: Munsat, T. (ed.) Quantification of Neurological Deficit, pp. 271-283. Butterworth, Boston (1989)

20. Ware, J., Sherbourne, C.: The MOS 36 item short-form health survey (SF-36). I. Conceptual framework and item selection. Med. Care 30, 473-483 (1992)

21. van der Berg, B.: SF-6D population norms. Health Econ. 21, 1508-1512 (2012)

22. Walters, S., Brazier, J.: Comparison of the minimally important difference for two health state utility measures: EQ-5D and SF-6D. Qual. Life Res. 14(6), 1523-1532 (2005) 
23. Haskin, B., Harrison, M.: Huntington's Disease. Curr. Treat. Options Neurol. 2(1), 243-262 (2000)

24. Jensen, P., Fenger, K., Bolwig, T., Sørensen, S.: Crime in Huntington's disease: a study of registered offences among patients, relatives, and controls. J. Neurol. Neurosurg. Psychiatry 65, 467-471 (1998)

25. National Institute for Health and Care Excellence: Guide to the methods of technology appraisal 2013. National Institute for Health and Care Excellence, London (2013)
26. Enroll-HD. https://www.enroll-hd.org/ (2018). Accessed 27 Aug 2018

Publisher's Note Springer Nature remains neutral with regard to jurisdictional claims in published maps and institutional affiliations.

\section{Affiliations}

\section{Annie Hawton ${ }^{1}$ (D) . Colin Green ${ }^{1} \cdot$ Elizabeth Goodwin ${ }^{1} \cdot$ Timothy Harrower $^{2}$}

1 Health Economics Group, University of Exeter Medical School, University of Exeter, South Cloisters, St Luke's Campus, Magdalen Road, Exeter, Devon EX1 2LU, UK
2 Neurology, Royal Devon and Exeter NHS Foundation Trust, Barrack Road, Exeter, Devon EX2 5DW, UK 